\title{
Kerklike inspraak in teologiese opleiding en in die beoefening van teologie? ${ }^{1}$
}

\author{
J. Smit \\ Student: Teologiese Skool \\ Potchefstroomse Universiteit vir $\mathrm{CHO}$ \\ POTCHEFSTROOM \\ E-pos: cjsmit@lantic.net
}

\begin{abstract}
Should the teaching and practice of theology be dictated by the church?

In this article it is argued that the practice of theology as a science, based on the presupposition that the Bible is the word of God, is inherently part of the calling and responsibility of the church. Therefore, practising theology as a science rooted in faith should also be ecclesiastically subservient to theology in general, and should indicate the way for the training of ministers of the Word. In this article it is argued that practising theology as a science rooted in faith is not to be regarded as an old-fashioned approach as this way of practising theology can be related to one of the positive trends in post-modernism: the increasing need for expressed presuppositions. This view stands in opposition to the rationalistic approach of theology in which the Bible is seen as a collection of texts of historical origin. According to the rationalistic view point, the Bible represents a collection of texts which reflect narratives of people's experiences and should be studied historically-critically. Thus the Bible becomes an object of rational analysis. Should the focus of theology (in contemporary postmodern times) move to the phenomenon of religions emphasizing rational analysis, churches will have to take the sole responsibility for the training of future ministers - even if the consequence implies that the involvement of universities in theological training be excluded.
\end{abstract}

1 Referaat gelewer voor die Teologiese Skole Kongres 2000 te Stellenbosch. 4 Augustus 2000. 


\section{Kontekstualisering}

Die postmodernisme, die nuwe era waarin ons lewe, word onder meer gekenmerk deur 'n nuwe spiritualiteit. In hierdie spiritualiteit gaan dit nie soseer om watter godsdiens beoefen word nie, maar meer oor hoe die mens sy behoefte aan spiritualiteit kan bevredig² (Adam, 1995:11).

'n Neerslag van hierdie spiritualiteit blyk ook in die Suid-Afrikaanse samelewing: die Suid-Afrikaanse Grondwet ${ }^{3}$ bepaal naamlik dat alle godsdienste gelykwaardig is en sodoende de jure as geldige alternatiewe beskou moet word. Dat hierdie gedagtegang ook al hoe meer in die denke van gereformeerde mense leef, blyk uit die standpunte wat deur Willem de Klerk in die Vreemde God en sy mense (1998) gestel word:

In ander godsdienste lê die voetspore van die Here God" en ... "Die Here se Gees werk ook in ander godsdienste. Hy aanvaar hulle deur die verdienste van Christus. Dit maak nie saak of die mense in Christus glo nie, want uit genade gee Hy Christus se belofte aan díe wat Hy verkies (De Klerk, 1998:47).

Dit is ook betekenisvol dat die Wêreldparlement van Godsdienste (WPG) aan die einde van 1999 in Kaapstad plaasgevind het. Die WPG aanvaar en beklemtoon die totale gelykwaardigheid van alle godsdienste. Hierdeur word die groeiende siening in die Suid-Afrikaanse samelewing, waarvolgens die verskillende godsdienste as alternatiewe beskou moet word, versterk.

Genoemde omlyning teken omstandighede wat die vraag al hoe meer na vore laat kom of teologiese fakulteite aan universiteite vir die nuwe godsdiensneutrale Suid-Afrikaanse regering nie al hoe minder bekostigbaar gaan word nie. Sal teologiese fakulteite in die toekoms nie al moeiliker deur die regering gesubsidieer kan word, sodat die klem in staatsgesubsidieerde teologiebeoefening dan eerder op die verskynsel van godsdienste as op die beoefening van teologie sal val nie?

\section{Probleemstelling}

Uit die voorgaande kontekstualisering as raamwerk vir die tema, kom dié aktuele probleemstelling na vore: Behoort kerke inspraak te hê in teologiese opleiding aan universiteite - en derhalwe ook in die beoefening van die teologie?

2 Kyk hieroor die standpunte van: Toffler, 1971; Toffler, 1980; Toffler, 1990; Vorster, 1996 en Herholdt, 1998.

3 Grondwet van Suid-Afrika, wet 108 van 1996, art. 15 (1)(b). 
Hierdie sentrale probleemstelling roep die volgende vrae op:

- Moet die kerke nie in die toekoms daaraan dink om die teologiese fakulteite kerklik te inkorporeer en kerklik te bedryf nie?

- Kan die kerk wetenskap bedryf en lê dit in die bevoegdheidsfeer van kerkwees?

- Hoort die beoefening van die wetenskap, ook teologie, nie slegs tuis in die bevoegdheidsfeer van universiteite nie?

- Gaan kerke, wat 'n "geloofsbedryf" is, hulleself nie in botsing bring met die algemene wetenskappe, wat 'n rasionele bedryf is nie?

\section{Uitgangspunt}

Om 'n antwoord op dié probleemstelling te bedink, is die regte vertrekpunt noodsaaklik. Uiteraard neem ons as vertrekpunt die Bybel én as 'n geloofsdokument én as 'n bundeling van historiese tekste wat wetenskaplik bestudeer kan word (vgl. NGB artt. 3, 4, 5, 7 - kyk Guido de Bres [1561]).

Die Bybel bied verskillende sleutels vir die vraagstuk van die verhouding van geloof en wetenskap. Om nie wydlopig te raak nie word hier slegs een voorbeeld uit die Ou Testament en een voorbeeld uit die Nuwe Testament geneem.

- Psalm 36:10b (1953-vertaling):

$\ldots$ in $u$ lig sien ons die lig

en

- Hebreërs 11:3(1983-vertaling):

Omdat ons glo, weet ons dat die wêreld deur die woord van God geskep is ...

Die kenbron-lig van Psalm 36 dui op die openbaring van God (vgl. Ridderbos, 1955:315) terwyl die geregtigheid deur die geloof in Hebreërs 11 eweneens op die openbaring van God dui (vgl. Calvyn, 1972:162). Hieruit blyk dat die raakpunt tussen die twee tekste, ook gesien uit die samehang van die Ou en Nuwe Testament, in God se openbaring as kenbron lê. Hier dui God se openbaring, en meer spesifiek sy Woordopenbaring, nie op kenbron van alles in die veelduidige skepping nie, maar wel op kenbron van veral die oorsprong en betekenis van alle dinge. 


\section{4. 'n Oorsigtelike verskil in die benaderingswyse van die teologiese wetenskappe en die algemene wetenskappe}

Die taak van die teologiese wetenskappe is om die Woord van God te bestudeer, om sy openbaringsraad na te vors en om dus onder meer die sin en bestemming van onsigbare dinge na te vors (Schulze, 1995:23). Hebreërs 11:3 sê: "Omdat ons glo weet ons". Hier praat die Bybel oor 'n wete(nskap) wat op geloof berus en selfs deur geloof bepaal word. 'n Wetenskap wat impliseer "Omdat ons glo, weet ons dat die wêreld deur die woord van God geskep is: die sigbare dinge het dus nie ontstaan uit iets wat ons sien nie" (Heb. 11:3).

Die Ou Testament sê: In u lig sien ons die lig, dit wil sê, omdat God sê, weet ons. Weereens staan 'n wete wat op geloof berus, in die sentrum.

Presies die teenoorgestelde standpunt is in die wetenskappe oor die algemeen gangbaar. Die sekulêre, algemene wetenskappe het oor die algemeen die taak om die sigbare dinge in hulle oorspronge, samehange en funksionerings te bestudeer (Stoker, 1961:134). Hierdie wetenskappe sê: Omdat ons weet, glo ons (vgl. Popma, 1956; Cairns, 1981). Hierdie wetenskappe redeneer vanuit kognitiewe prosesse en verklaar dat hulle wetenskaplik gesproke, alleen dit kan glo wat hulle weet; dit wat bewysbaar is.

Teologie kan wel bedryf word soos die algemene wetenskappe, naamlik op grond van die wete; dit wat uit die sigbare kenbaar en bewys kan word. 'n Teologiebeoefening met hierdie uitgangspunt en benaderingswyse kan nie ontken word as 'n teologie nie.

Om hierdie standpunt te illustreer, enkele voorbeelde:

- Voorbeeld 1: Die histories-kritiese metode van Skrifverklaring kan waarskynlik herlei word na die opkoms van die rasionalisme (met die gepaardgaande beklemtoning van wetenskap en metode) in die sestiende en sewentiende eeu (vgl. Copernicus, Descartes, Spinoza) (De Jonge, 1982:73). Die histories-kritiese metode vind beslag deur die werk van F.C. Baur, die grondlegger van die Tübinger Skool. Deur krities van bronne gebruik te maak poog Baur om die werklike historiese gebeurtenisse te rekonstrueer en sodoende 'n dogmaties onbevooroordeelde beeld van die vroeë Christendom te skets. Deur sy teorie poog hy om aan die wetenskaplike eis van objektiwiteit te voldoen (De Jonge, 1982:74, 75). De Jonge (1982:82) sê oor die histories-kritiese skool: "Niet alleen het unieke, maar ook het principieel Unieke is voor de historisch-kritische methode niet grijpbaar". 
- Voorbeeld 2: Schleiermacher4 se "vertaling" van die evangelie in wetenskaplike taal soos in die Redevoeringe5 (Van Wyk, 1993:289), laat die vraag ontstaan of Schleiermacher nog waarlik teologie beoefen. Sy teologie is as't ware 'n gesprek met die wetenskaplikes van sy tyd waarin hy poog om die evangelie op 'n rasioneel aanvaarbare wyse aan hulle te bied. Schleiermacher se beklemtoning van die subjektiewe en sy fokus op die antropologie, sy beklemtoning van die godheid eerder as van God dra deurlopend die stempel van rasioneel wetenskaplike teologie - 'n poging om vanuit die waarneembare, die kognitiewe, die rasionele, by God uit te kom. Ten spyte van Schleiermacher se unieke beklemtoninge merk Van Wyk (1993:291) egter op dat kennis van Schleiermacher se teologie "... onontbeerlik is vir die juiste verstaan van die twintigste-eeuse teologie".

Die vraag is egter of die kerke hulle predikante wil of kan oplei met 'n teologie wat bloot op die rede berus? Of het die kerk die roeping om predikante op te lei en teologie te beoefen vanuit die geloofstandpunt, naamlik "In u lig sien ons die lig" en "Omdat ons glo, weet ons ..."?

As uitgangspunt word in hierdie artikel 'n teologie gestel wat as geloofswetenskap beoefen word (vgl. Oberholzer, 1994:27). Onder "geloofswetenskap" moet verstaan word die beoefening van die teologie wat op 'n geloofstandpunt berus en waarin die Bybel as die Woord van God erken word.

\section{Kerk en teologie}

\subsection{Twee breë strome}

Vir die doel van díe artikel word tussen twee breë teologiese denkstrome onderskei.

- Eerstens: Die bloot rasioneel wetenskaplike teologie aanvaar die Bybel as ' $n$ bundel tekste van historiese oorsprong wat ten dele bestaan uit verhale en legendes wat mense uit hulle ervaringswêreld met God opgeteken het en wat histories-wetenskaplik bestudeer moet word (vgl. Aitken, 1991:227-239).

- Tweedens: Teologie as wetenskap wat beoefen word vanuit die perspektief van die geloof (oftewel die kerklik diensbare teologie) gaan van die standpunt uit dat die Bybel 'n bundel tekste is waarin God Homself deur die geskiedenis bekend gemaak het (vgl. Bavinck,

\footnotetext{
$4 \quad$ Kyk McGrath (1994:36-45).

5 Schleiermacher (1990).
} 
1967:584). As sodanig word die Bybel as die Woord van God aanvaar, maar wel ook as 'n bundel tekste wat teologies bestudeer kan word.

Van Deventer (1996:441-456) wys onder andere daarop dat die teologiebeoefening vanuit geloofsgronde én vanuit wetenskaplike bewysgronde ook sinvol van eksegetiese tradisies buite hierdie benaderingsmodel gebruik kan maak. So kan positiewe aspekte van die histories-kritiese metode, byvoorbeeld die bestudering van die historisiteit, genres, en die totstandkoming van Bybelgedeeltes, sinvol in grammaties-historiese eksegese gebruik word. Die vertrekpunt in die wetenskaplike teologiebeoefening vanuit 'n geloofstandpunt bly egter die belydenis dat die Bybel die Woord van God is - 'n uitgangspunt waaraan elke bepaalde eksegetiese en hermeneutiese metode gebonde geag moet word.

Teologiese studente word in die eerste plek opgelei om predikante en teoloë in kerke te wees. Ons probleemstelling vra: Het die kerke iets te sê oor die opleiding van predikante, veral oor die uitgangspunt van die teologiese opleiding? Die kerk se primêre doel in hierdie wêreld is om self in die geloof opgebou te word en om buitestanders tot die geloof te lei. Kan die kerk hierdie taak uitvoer met 'n neutrale beoefening van teologie wat bloot op die rede berus?

\subsection{Die verhouding tussen kerk en teologie}

In die gereformeerde wêreld word soms aanvaar dat die beoefening van teologie nie die taak van die kerk is nie (Malan, 1977:8). Hierdie standpunt realiseer prakties in twee modelle waarin die verhouding tussen kerk en teologie tot uitdrukking kom, naamlik dié van Kerklike fakulteite en die duplex ordo-model (kyk Schulze, 1995:6-8).

Kerklike fakulteite is in die Roomse tradisie ontwikkel en staan onder beheer van die Rooms-Katolieke biskopkonferensies. Universiteit en teologiese fakulteit word volgens hierdie model deur die kerk opgerig en bestuur. Op grond van die leergesag (magisterium) wat Rome aan die kerk toeken, kan (alleen) die kerk die Bybel gesagvol uitlê en leer teologiese fakulteite dus die standpunte van die kerk - ook in die eksegese (Schulze, 1995:7).

Die duplex ordo-model word deur die Nederlandse Ryksuniversiteit en die Universiteit van Amsterdam toegepas. Dié teologiese fakulteite is sedert 1876 omvorm tot fakulteite vir godsdienswetenskappe waarin die klem val op die Godsbewussyn in die mens en die wyse van Godsverering (Schulze, 1995:7). Wentzel (aangehaal deur Schulze, 1995:7, 8) 
merk oor hierdie tweeslagtige kompromismodel (tussen die sekularisme en rasionalisme van die Verligting) die volgende op (Schulze, 1995:8):

... [Hierdie] kromme constructie ... dwingt de studenten zich te oefenen in de crisis van het christendom en te leven in de spanning tussen menslijke religieusiteit en christelijk geloof. De schaduzijden zijn: het uiteenvallen van exegese in de zogenaamde strikt-wetenskaplijke en bijbelse theologie; het misverstand dat er onderscheiden zou moeten worden tussen universitaire en kerklijke theologie ...

Schulze (1995:6) is van mening dat teologie deur die loop van die geskiedenis, vanaf die tyd van die Apostoliese Vaders, deur "kerkdienaars" beoefen is. So is die leer van die vier ampte 'n produk van die eksegese en oortuiging van die Reformatore. Indien die diens van die doktore (professore) nie 'n taak van die kerk is nie, bly die vraag onbeantwoord waarom die kerkorde (artt. 2, 18) hierdie diens vermeld en omskryf. 'n Derde model waarin die standpunt van Schulze (1995:7) prakties neerslag vind, is dié van teologiese skole.

Hoewel teologiese skole aan universiteite verbind is en soms ook subsidie van die regering ontvang, berus die toesig en beheer van die teologiese skole by die kuratore en kieskollege van die algemene sinode van die kerke omdat bedienaars van die Woord daar opgelei word. Histories gesien, het teologie uit die kerk ontstaan en staan dit in diens van die kerk. A-konfessionele teologiebeoefening het meesal nie enige nut vir die kerk nie en is soms selfs gevaarlik vir die kerk om te gebruik (Schulze, 1995:8).

\subsection{Doel van teologiese opleiding}

In die era van die postmodernisme word nie alleen die behoefte aan spiritualiteit beklemtoon nie, maar is daar ook 'n toenemende vraag na die uitgangspunte van die benadering tot probleemstellings. Wêreldwyd vra wetenskaplikes - ook fisici, chemici en wiskundiges - na die voorveronderstellings, die vertrekpunte van waaruit die wetenskap benader word. Wanneer ons sê dat ons die teologie in diens van die kerke gaan beoefen met die gestelde uitgangspunt ... in u lig sien ons die lig en omdat ons glo weet ons ... is dit nie 'n oudmodiese benaderingswyse nie, maar eerder 'n invalshoek wat steeds nuut en kraakvars is in die wetenskaplike wêreld van vandag.

Die kerk moet teologie beoefen om predikante op te lei om die woord van God te verklaar - in die eerste plek nie as wetenskaplikes nie, maar as wetenskaplik gevormde gelowiges (vgl. Le Roux, 1994:589). 
Die beoefenaars van die eerste denkrigting waarna verwys is, die bloot rasioneel wetenskaplike teologie, streef in die beoefening van hulle teologie na 'n suiwer wetenskaplike doel. Hulle uitgangspunt berus op die suiwer kognitief wetenskaplike standpunt en daardeur word die historieskritiese metode aanvaar as die wetenskaplike evangelie waaraan alle ander metodes onderhewig gestel word.

Die doel van kerke (tweede denkrigting) om predikante op te lei en sodoende hulle roeping uit te voer, maak teologiebeoefening as wetenskap, maar vanuit die perspektief van die geloof, noodsaaklik as metode. Bavinck (1967:589) beskryf hierdie vertrekpunt vir die teologie soos volg:

Begrijpen doen wij zeer weinig ... Begrijpen sluit verwondering en bewondering uit. Ik begrijp ... wat vanzelf spreekt en volkomen natuurlijk is. Dikwerf [= dikwels - JS] hou het begrijpen op, naarmate men dieper onderzoekt. Wat vanzelf sprak, blijk gansch ongewoon en wonderlijk te zijn ... Waar echter het begrijpen ophoudt, blijft er tog noch plaats voor het kennen en bewonderen. Zoo is het ook in de theologie. In het openbaring is ... ons onthuld, het mysterie van Gods genade. Wij zien het, het treed ons als eene realiteit in de geschiedenis en in het eigen leven tegemoet; maar wij deurgronden het niet.

Die geloofsuitsprake van die kerk (byvoorbeeld die belydenisskrifte) beperk nie die misterie van God se genade nie, maar dit sê wel dat die beoefening van die teologie (wetenskap) in diens van die kerke gedra word deur dieselfde geloof aan die Woord van God as waardeur kerklike geloofsuitsprake gedra word. Geloof vorm dus die basis vir "geloofswetenskaplike" teologie. Soos Barth (aangehaal deur McGrath, 1994: 131) eens opgemerk het, is teologie (hier beskryf as geloofswetenskaplike teologie) fides quaerens intellectum (faith seeking understanding). Hier moet dit duidelik gestel word dat niks, behalwe die Woord van God, absoluut is nie. Dus ook nie kerklike geloofsuitsprake nie en ook nie die beoefening van die teologie nie. Albei is per slot van sake die resultaat van ons verstaan, dit wil sê die interpretasie en verklaring van die Bybel as die Woord van God (vgl. Bavinck, 1967:583).

Om die Woord van God te verklaar, lê in die hart van die kerk se opdrag. Kerke kan dus nie op 'n verantwoordelike wyse hulle roeping nakom in die Woordverkondiging en op elke vlak van die kerklike bediening as hulle nie sou toesien dat die bedienaars van die Woord teologies opgelei word nie. Dit lê in die aard en roeping van kerkwees om predikante vanuit 'n geloofsuitgangspunt op te lei. 


\section{Universitêre en/of kerklike opleiding?}

In die staatkundige bedeling in Suid-Afrika voor 1994 het die regering universiteite tegemoet gekom om teologie as wetenskap te huisves. Hoe goed die gebruik ook al bedoel was, kon dit aanleiding gee tot die beoefening van teologie as 'n bloot neutrale wetenskap, dit wil sê 'n bloot krities-historiese wetenskap. Omdat die kerke in Suid-Afrika egter hierop bedag was, het die kerke (kerke uit die gereformeerde tradisie) ooreenkomste met universiteite aangegaan waarvolgens hulleself die verantwoordelikheid aanvaar het vir die beoefening van die teologie en die toesig daaroor deur middel van die toesig deur kuratoriums en die beroeping van professore.

Kerke het dus nooit van hulle verantwoordelikheid afgesien om predikante in die beoefening van kerklik diensbare teologie op te lei nie. Indien kerke die teologiese vorming van die Woordbedienaars sonder meer aan universiteite sou oorlaat, sou die geloofsuitgangspunt mettertyd prysgegee word. Deist (1994:64) het die opmerking gemaak dat "Teologiese studente wat wetenskaplik deur universiteite opgelei word, ... dus nie binne die universitêre raamwerk denominasioneel 'afgerig' [kan] word nie".

Tans bevind verskeie teologiese fakulteite hulle in 'n posisie van onderhandelinge waarin beding word vir die voortbestaan van teologiese fakulteite en verwante departemente aan universiteite met voortgesette subsidiëring. Indien hierdie onderhandelinge slaag, sal teologiese skole verbonde aan universiteite steeds die beste weg bly om studente op te lei, aangesien opleiding van hoogstaande gehalte sodoende verseker word (Van Rooy, 2000:24).

\section{Gevolgtrekkings as 'n basis vir moontlike antwoorde}

Die voorlopige gevolgtrekking kan gemaak word dat die beoefening van teologie vir die doel van die kerk, primêr om predikante op te lei, by die kerk berus.

- Die wetenskap van teologiebeoefening vanuit die perspektief van die geloof is 'n fundumentele geloofsuitgangspunt vir die beoefening van kerklik diensbare teologie. In die postmodernisme, die tyd waarin religieuse grondmotiewe as vertrekpunte aanvaar word, sal die wetenskap van teologiebeoefening met inagneming van die geloofsdimensie nie soseer bevraagteken word as die konfessionele belyning waarbinne hierdie teologie beoefen word nie. Myns insiens kan gelowiges nie anders as om konfessioneel-bindende teologie te bedryf nie aangesien die teologie andersins in die postmodernisties 
aanvaarbare duplex ordo-model sal verval (vgl. Schulze, 1995:21, 22).

- Die opleiding van teologiese studente word tot 'n groot mate bepaal deur die spesifieke kerkgemeenskap se standpunt oor die verhouding tussen Skrifgesag en kerkgesag. Gereformeerdes buig onder die gesag van die Woord van God en volg dus die model van teologiese skole vir die opleiding van predikante waardeur die kerk primêr aanspreeklik is vir die opleiding.

- Die opleiding van predikante is onlosmaakbaar deel van die roeping van die kerk en kan nie aan ander organisasies soos universiteite oorgedra word nie.

- Dit is die opdrag van die kerk om teoloë op te lei wat wetenskaplik gevorm is sonder dat díe geloofsuitgangspunt gekompromitteer word.

\section{Moontlike antwoorde}

Aan die begin van hierdie artikel het vier vrae rondom die sentrale probleemstelling uitgekristaliseer. Die eerste vraag was:

- Moet die kerke nie in die toekoms daaraan dink om die teologiese fakulteite kerklik te inkorporeer en kerklik te bedryf nie?

Op hierdie vraag het dié antwoord duidelik geword: die kerke het die verantwoordelikheid om, indien dit nodig mag wees, teologiese opleiding kerklik te bedryf. Dit sluit nie noodwendig universitêre betrokkenheid uit nie, maar dan op kerklike voorwaardes.

- Kan die kerk wetenskap bedryf en lê dit in die bevoegdheidsfeer van kerkwees?

Dit is 'n primêre roeping van die kerk om teologie te beoefen. Wie begin om die Woord te verklaar, is reeds besig met teologie. Die kerk kan nie anders as om die opleiding van sy Woordbedienaars met die oog op Woordverklaring te begrond in die uitgangspunte van die geloof én wetenskap nie. Hiersonder sou die Woordverklaring wetenskaplik ongeldig word.

- Hoort die beoefening van die wetenskap, ook teologie, nie slegs tuis in die bevoegdheidsfeer van universiteite nie?

Dit is ' $n$ oudmodiese standpunt dat wetenskapsvorming juis aan 'n universiteit moet geskied. Vandag word gedifferensieerde en wetenskaplik verantwoorde opleiding ook aangebied by technicons, opleidingskolleges en ander opleidingsentra op tersiêre vlak. Kerke moet 'n oop 
oog daarvoor hê om nie die ontwikkeling wat aan universiteite plaasvind te misken nie, maar om onder meer die nuutste ontwikkelings van opleidingsmetodes in hulle eie opleiding te inkorporeer.

- Gaan kerke, wat 'n geloofsbedryf is, hulleself nie in botsing bring met die algemene wetenskappe, wat 'n rasionele bedryf is nie?

Nee, teologie staan nie los van die kerk nie. Soos die algemene wetenskappe het ook die kerk die geleentheid om sy geloofsuitgangspunte openlik op die tafel te plaas. In die postmodernisme word die rasionele nie meer as die finale maatstaf beskou nie, maar val die klem ook op voorwetenskaplike uitgangspunte, religieusiteit en persoonlike ervaring.

\section{Slot}

Geloof en wetenskap (teologie) is nie aparte entiteite wat in opposisie staan nie, maar soos tans in die postmodernisme erken word, bepaal geloofsuitgangspunte wetenskapbeoefening. In die gereformeerde tradisie geld die geloofsuitgangspunt dat die Bybel die Woord van God is en moet teologie altyd aan die norm (die Woord) getoets word om kerklik diensbaar te kan wees. Teologie is dus in wese 'n kerklike handeling wat die Woord as openbaringsmiddel, waardeur God met die mens kommunikeer, ondersoek én veronderstel nie 'n neutrale en objektiewe Bybelkennis wat God self tot studie-objek manupileer nie (Schulze, 1995: 23). Teologie staan in diens van die kerk om die wonder van God se openbaring gelowig na te speur en om dalk 'n vingerdiepte verder in hierdie misterie te kan sien.

\section{Bibliografie}

ADAM, A.K.M. 1995. What is postmodern Biblical criticism? Mineapolis : Fortress.

AITKEN, D. 1991. History, truth and the rational mind. Theologische Zeitschrift, 47(3): 226-253.

BAVINCK, H. 1967. Gereformeerde Dogmatiek. Eerste deel. Vijfde onveranderde druk. Kampen : Kok.

CAIRNS, Earl E. 1981. Christianity through the centuries. A history of the Christian church. Grand Rapids : Academie Books Zondervan.

CALVIJN, Johannes. 1972. Verklaring van de Bijbel door Johannes Calvijn. Uitlegging op de Zendbrieven van Paulus aan Timotheus, Titus, Filemon en Hebreën. Naar de uitgaven der Oude-Hollandsche overzetting van J.D. en J.F. in tegenwoordige spelling, door A.M. Donner. Goudriaan : De Groot. p. 1-219.)

DEIST, F.E. 1994. Moet teologiese opleiding kerklik konfesioneel wees? Hervormde Teologiese Studies, 50(1 \& 2):53-67.

DE BRES, Guido. 1561. Nederlandse Geloofsbelydenis. (In Die Berymde Psalms. 1976. Kaapstad : NG-Kerk Uitgewers. p. 488-516.)

DE JONGE, M. 1982. De historisch-kritische methode. (In Klijn, A.F.J, red. Inleiding tot de studie van het Nieuwe Testament. Kampen : Kok. p. 71-85.) 
DE KLERK, Willem. 1998. Die vreemde God en sy mense. Kaapstad : Humann \& Rousseau.

GRONDWET VAN SUID-AFRIKA

Kyk SUID-AFRIKA. 1996.

HERHOLDT, M.D. 1998. Postmodern theology. (In Maimela, S. \& König, A., eds. Initiation into theology. The rich variety of theology and hermeneutics. Pretoria : Van Schaik. p. 215-139.)

LE ROUX, J.H. 1994. Die aard en plek van teologiese opleiding aan 'n universiteit. Nederduitse Gereformeerde Teologiese Tydskrif, 35(4):589-599, Des.

MALAN, C.J. 1977. Kerk en teologie. (Opsomming van referate gelewer by die G.E.S.) In die Skriflig, 11(42):5-9.

McGRATH, Alister E. 1994. The making of modern German Christology 1750-1990. Grand Rapids : Zondervan.

OBERHOLZER, J.P. 1994. Tendense in teologiese opleiding: Die pad vorentoe. Hervormde Teologiese studies, 50(1 \& 2):27-38.

POPMA, S.J. 1956. Aufklärung. Christelike Encyclopedie. Deel 1. Kampen : Kok. p. 373-374.

RIDDERBOS, J. 1955. De Psalmen. (In Aalders, G.CH., Gispen, W.H. \& Ridderbos, J. Commentaar op het Oude Testament. Deel 1. Kampen : Kok. p. 308-316.)

SCHLEIERMACHER, F. 1990. Over de religie: Redevoering tot de ontwikkelden onder haar verachters. (Vertaling A.A. Willems.) 's Gravenhage : Meinema.

SCHULZE, L.F. 1995. Inleiding in die grondslag van die gereformeerde teologie. In die Skriflig, 29(1 \& 2): .

STOKER, H.G. 1961. Beginsels en metodes in die wetenskap. Potchefstroom : ProRege Pers.

SUID-AFRIKA. 1996. Constitution of the Republic of South Africa as adopted by the Constitutional Assembly on 8 May 1996 and as amended on 11 October 1996. Pretoria : Government Printers.

TOFFLER, A. 1971. Future Shock. London: Pan Books.

TOFFLER, A. 1980. The third wave. London: Collins.

TOFFLER, A. 1990. Powershif: knowledge, wealth, and violence at the edge of the 21st century. New York : Bantam Books.

VAN DEVENTER, H.J.M. 1996. 'n Paradigma vir gereformeerde teologiese wetenskapsbeoefening. Koers, 61(4):441-456.

VAN ROOY, Herrie. 2000. Wat is die toekoms van teologie-opleiding in Suid-Afrika? Woord en Daad : 23-24, Somer.

VAN WYK, J.H. 1993. Boekbespreking van: Schleiermacher, F. Over de religie: Redevoering tot de ontwikkelden onder haar verachters. In die Skriflig, 27(2):289-291.

VORSTER, J.M. 1996. Is die kerk funksioneel? Potchefstroom : Potchefstroom Teologiese Publikasies.

\section{Kernbegrippe:}

teologie: onderrig en beoefening

teologie: rol van dogma en kerk

teologiebeoefening: as wetenskap en gegrond in geloof

\section{Key concepts:}

theology: role of doctrine and church

theology: studied as science and rooted in faith 
theology: teaching and practice 